\title{
Error evaluation in acoustic positioning of a single transponder for seafloor crustal deformation measurements
}

\author{
Takuji Yamada ${ }^{1 *}$, Masataka Ando $^{2}$, Keiichi Tadokoro $^{2}$, Kazutoshi Sato $^{1 *}$, Takashi Okuda $^{2}$, and Kazuo Oike ${ }^{1}$ \\ ${ }^{1}$ Department of Geophysics, Graduate School of Science, Kyoto University, Kyoto 606-8502, Japan \\ ${ }^{2}$ Research Center for Seismology and Volcanology, Graduate School of Science, Nagoya University, Nagoya 464-8602, Japan
}

(Received March 8, 2002; Revised August 29, 2002; Accepted September 6, 2002)

\begin{abstract}
The observation of seafloor crustal deformation is very important to understand plate motions, nucleation processes and mechanisms of great interplate earthquakes as well as the activities of submarine volcanoes. We have been developing an observation system for seafloor crustal deformation. This system consists of two main components; (1) kinematic GPS positioning of an observation vessel and (2) accurate acoustic measurements of distances between a transponder attached on the side of the vessel (onboard station) and one located on the ocean bottom (seafloor station). In this study, we performed numerical simulations to estimate measurement errors with acoustic positioning assuming acoustic velocities in the sea water and the distribution of observation points around the single seafloor station. We found that the position of the seafloor station which we can obtain by analyzing travel-time data might have around 18-cm discrepancy with respect to its "true" position. Colombo et al. (2001) reported that the position of the vessel can be determined with about $10-\mathrm{cm}$ error by kinematic GPS positioning. These results indicate that the system should be able to detect seafloor crustal deformation much larger than 28 $\mathrm{cm}$, including pre-, co-, and post-seismic slips due to the large earthquakes at subduction zones, slow and silent earthquakes, etc. Therefore, we emphasize the importance of continuous observations with a nationwide geodetic observational network for seafloor crustal deformation.
\end{abstract}

\section{Introduction}

Recent advances in hardware and data analysis techniques for the Global Positioning System (GPS) have made possible the installation of a dense observation network in Japan (Miyazaki and Hatanaka, 1998) providing detailed on-land deformation patterns that contribute to many geophysical studies including interplate coupling (e.g., Ito et al., 1999; Nishimura et al., 1999; Ozawa et al., 1999), slow slip events (e.g., Heki et al., 1997; Hirose et al., 1999; Dragert et al., 2001; Ozawa et al., 2001a, 2001b; Thatcher, 2001), etc. On the other hand, space-based geodetic techniques, including GPS and Very Long Baseline Interferometry (VLBI), use electromagnetic waves that cannot penetrate significantly into deep sea water. This limits the observation of crustal deformation to land, so precise seafloor crustal deformations associated with large earthquakes in subduction zones and submarine volcanic activities are unknown. Observations of seafloor crustal deformation near their sources are important to elucidate the nucleation processes and mechanisms of great interplate earthquakes, as well as, the activities of submarine volcanoes.

The seafloor crustal deformation can be observed mainly by three methods as follows: (1) Observations of strains by strain meters and tiltmeters installed in seafloor boreholes

*Now at Research Center for Earthquake Prediction, Disaster Prevention Research Institute, Kyoto University, Kyoto 611-0011, Japan.

Copy right $(\mathrm{C}$ The Society of Geomagnetism and Earth, Planetary and Space Sciences (SGEPSS); The Seismological Society of Japan; The Volcanological Society of Japan; The Geodetic Society of Japan; The Japanese Society for Planetary Sciences. (e.g., Shinohara et al., 2000). This approach is unsuitable for the observation network of seafloor crustal deformation because it requires a great deal of labor and is too costly to install in many places. (2) Acoustic measurements of the distances between two stations fixed on the seafloor (e.g., Fujimoto et al., 1995). Relatively accurate distances can be obtained by this method because the sound speed near the seafloor has a little perturbation both spatially and temporally, since temperature and salinity are more stable in the deep sea than those near the surface (e.g., Greenewalt and Gordon, 1978; National Astronomical Observatory, 2002). On the other hand, sound speed in the deep sea water below $1,000 \mathrm{~m}$ is dominantly controlled by pressure and proportional to depth, so rays bend upward in the deep ocean. As a result, it is unsuitable in the case that two stations are separated far away because seafloor can obstruct the rays. Furthermore, we should pay close attention in installing stations if there are obstacles including submarine knolls, which can obstruct acoustic rays, too. (3) Determining positions of stations fixed on the seafloor by accurate acoustic measurements of distances between an observation vessel and stations on the seafloor. The position of the observation vessel is determined by kinematic GPS positioning. We can obtain the deformation pattern for seafloor stations installed over a wide area by this method. It provides a different spatial and temporal coverage than that of method (2). The two methods complement each other. Observations of seafloor crustal deformation based on this method have been carried out by many groups (e.g., Spiess et al., 1998; Obana et al., 2000; Asada and Yabuki, 2001; Tadokoro et al., 2001). Spiess et 


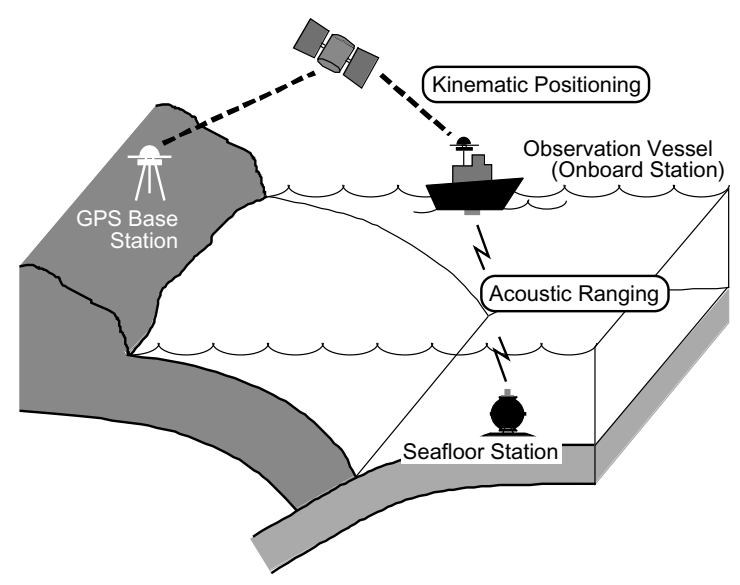

Fig. 1. Schematic view of the observation system for seafloor crustal deformation adopted by Tadokoro et al. (2001). The position of the observation vessel is determined by kinematic GPS. Acoustic ranging is carried out between a transponder attached on the vessel and a seafloor station.

al. (1998) uses a uniform azimuthal distribution of three or more transponders and determines their center as a reference point. They collect ranges from the center of the array on the sea surface so that coherent temporal changes in sound speed do not affect the horizontal positioning of the reference point. On the other hand, the approach adopted by Obana $e t$ al. (2000) and Tadokoro et al. (2001) involves positioning of a single seafloor transponder by moving the ship around the seafloor station, as shown schematically in Fig. 1. This approach does not need a fixed transponder array between repeated observations, although it is subject to systematic errors in not knowing the spatio-temporal variations of the sound speed.

In this paper, we will discuss errors due to acoustic positioning by using the observation system adopted in Tadokoro et al. (2001) (Fig. 1). This system consists of two main components; (1) positioning an observation vessel by kinematic GPS and (2) acoustic measurements of distances between an acoustic transponder attached on the observation vessel (onboard station) and one installed on the ocean bottom (seafloor station). The position of the seafloor station is determined by a way like a hypocenter determination.

This system contains two major observation errors, which are associated with the GPS positioning of the observation vessel and acoustic measurements between the onboard station and the seafloor station. In this study, we perform numerical simulations to investigate the primary observation errors of the acoustic measurements in positioning a single seafloor transponder.

\section{Acoustic Measurements}

The round-trip travel times of the ultrasonic waves from the onboard station to the seafloor station and back into the onboard station are measured by the following method (Fig. 2). The onboard station sends a 3.41-ms-long ultrasonic chirp wave with a gradual change in frequency (from 12 to $8 \mathrm{kHz}$; down-chirp wave). The seafloor station sends another chirp wave whose frequency changes from 8 to 12 $\mathrm{kHz}$ (up-chirp wave) after receiving the signal from the on-

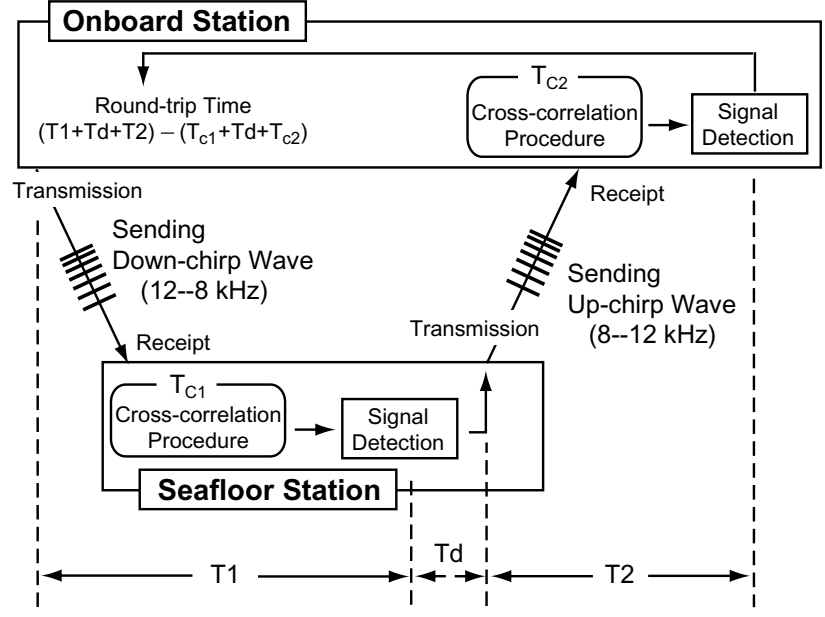

Fig. 2. Schematic illustration showing the principle of acoustic ranging measurements.

board station. The A/D conversion of signals is carried out at $37.5 \mathrm{kHz}$ sampling. This sampling interval corresponds to the uncertainty of $4.0 \mathrm{~cm}$ in distance for one way (from the onboard station to the seafloor one, or the opposite way) if we assume the sound speed in the sea as $1.5 \times 10^{3} \mathrm{~m} / \mathrm{s}$. The onboard transponder is installed at the end of a pole which is fixed on the side of the observation vessel. The onboard station sends signals repeatedly with a-few-second interval that is synchronized with a 1-pps GPS time server. The seafloor station detects signals by calculating coefficients of cross correlations between received signals and the noise-free signal. The seafloor station sends back a signal after $50 \mathrm{~ms}$ from receiving the signal from the onboard station. The onboard station also calculates the coefficient and a round-trip time is obtained. As a result, we can observe the acoustic distance between the onboard station and the seafloor station by taking into account the sound speed structure in the sea.

During an observation session the seafloor transponder is interrogated from the onboard transponder every few seconds. The interrogation interval can be adjusted to the depth. We release the clutch of the vessel and let it drift with an ocean current during the session. When the acoustic distance between the onboard station and the seafloor station becomes larger (incident angles become larger than about $45^{\circ}$ ), the vessel moves another point and resume interrogations. Using data from the entire session, we are able to obtain the precise position of the seafloor station by analyzing these acoustic measurements data with taking into account the position of the onboard station, which is calculated from the temporally changing position and attitude (yaw, roll, and pitch) of the research vessel.

\section{Numerical Simulations}

In the system, observation errors with acoustic measurements are divided into three parts, which are due to signal recognition, azimuthal coverage of observation lines, and spatio-temporal heterogeneities of the sound speed structure. We evaluate measurements errors due to these three factors by numerical simulations.

As we mentioned in the last section, signals are detected 
(a)

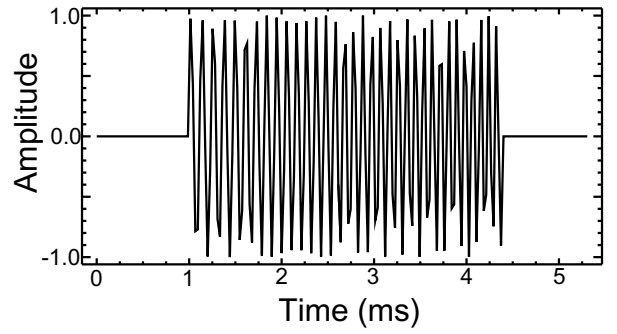

(b)

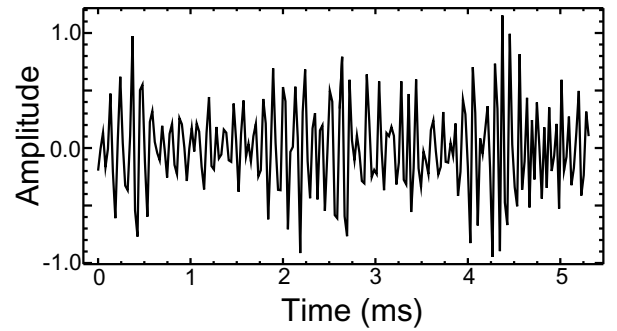

(c)

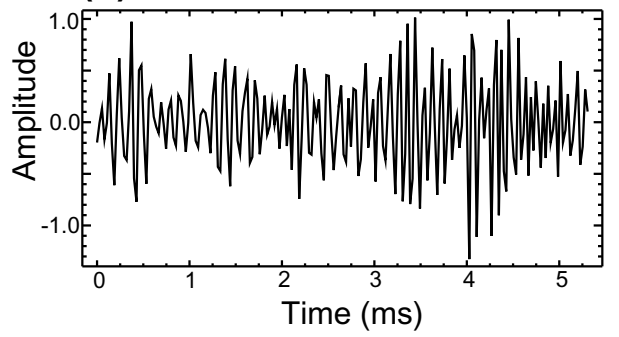

(d)

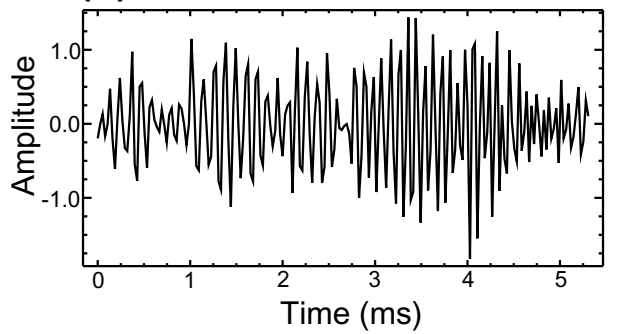

Fig. 3. Examples of acoustic waves which we used in the simulation. (a) Synthetic noise-free up-chirp wave. The length of the signal is 3.41 ms and the A/D conversion is carried out by $37.5 \mathrm{kHz}$ sampling. (b) Waveform of noises obtained at an experimental observation on October 23, 2000. This wave includes the frequency response of the transponder. (c) Synthetic waveform with an $\mathrm{S} / \mathrm{N}$ ratio of 0.5 . This waveform is composed of waves in Figs. 3(a) and (b) by adding them with an amplitude ratio of 2:1. (d) Synthetic waveform with an S/N ratio of 1.0.

by calculating coefficients of cross correlations between the noise-free original signal and received signals. The received signals are distorted by various acoustic noises, which degrade the precision of the travel time estimates. To determine the travel time resolution, we synthesize received signals by adding noises to noise-free signals and evaluate how accurately arrival times of signals are detected. We use real background sea noises recorded at our observation as noises in the simulation. Figure 3 shows examples of the waveforms used in the simulations.

To investigate the accuracy in determining the position of the seafloor station due to azimuthal coverage of observation lines and temporal heterogeneities of the sound speed, we synthesize data, determine the location of the seafloor station with $95 \%$ level, and evaluate the discrepancy from the "true" position. To simulate data, a Cartesian coordinate system $(X, Y, Z)$ is defined in which $X$ and $Y$ axes lie on the water surface and $Z$ axis directs upward, that is, a plane with $Z=0$ corresponds to the water surface. We assume that the seafloor station is located in $(0.00,0.00,-1500.00) \mathrm{m}$ and observation points lie on the water surface ranging from $-1,000 \mathrm{~m}$ to $1,000 \mathrm{~m}$ in both $X$ and $Y$ directions with every $200 \mathrm{~m}$ and $5 \mathrm{~m}$ along $X$ and $Y$ axes, respectively. So we imagine that we can obtain the data at 4,411 points. We consider layered velocity structures as in Figs. 4(a), (b), and (c), and calculate travel times from the seafloor station to each point, which corresponds to one of the onboard stations. White noise with a maximum amplitude of $0.20 \mathrm{~ms}$ (equivalent to about $30 \mathrm{~cm}$ in distance) is added to the calculated travel times. This is because we cannot correct the bending of the pole on which the onboard transponder is attached, though we monitor the roll and pitch of the vessel during the observation session. These errors with $0.20 \mathrm{~ms}$ correspond to the bending of the pole of $15 \mathrm{~cm}$ normal to the pole. We use these synthetic one-way "observed" data and analyze the

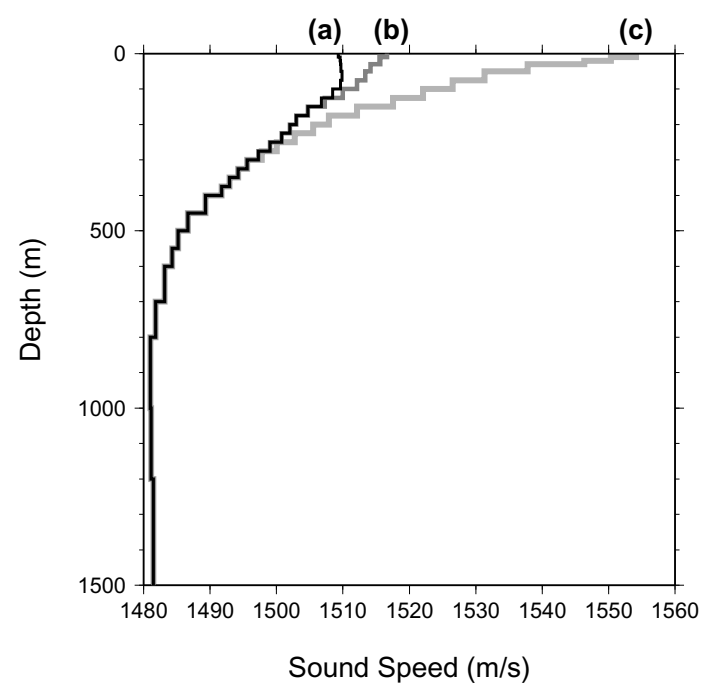

Fig. 4. Sound speed structures used in the simulation. (a) Sound speed profile calculated from the data that obtained by Conductivity Temperature Depth profiler (CTD) at an experimental observation in the Suruga bay on January 16, 2001. Conversion of the CTD data into sound speed was carried out according to the equation (1) (Del Grosso, 1974). (b) Sound speed profile with daily changes in temperature. (c) Sound speed profile with seasonal changes in temperature. Refer to the text and Table 1 in detail.

position of the seafloor station and evaluate the discrepancy between an observed position and the "true" one.

As we mentioned before, we disengage the clutch of the observation vessel and let it drift with an ocean current during the observation session in the sea. As a result, observation points (observation lines) are distributed almost in parallel if the ocean current is uniform in direction during the observation. Although velocities of tides may vary regionally, if we assume that the current is about 2.0 knots (about 


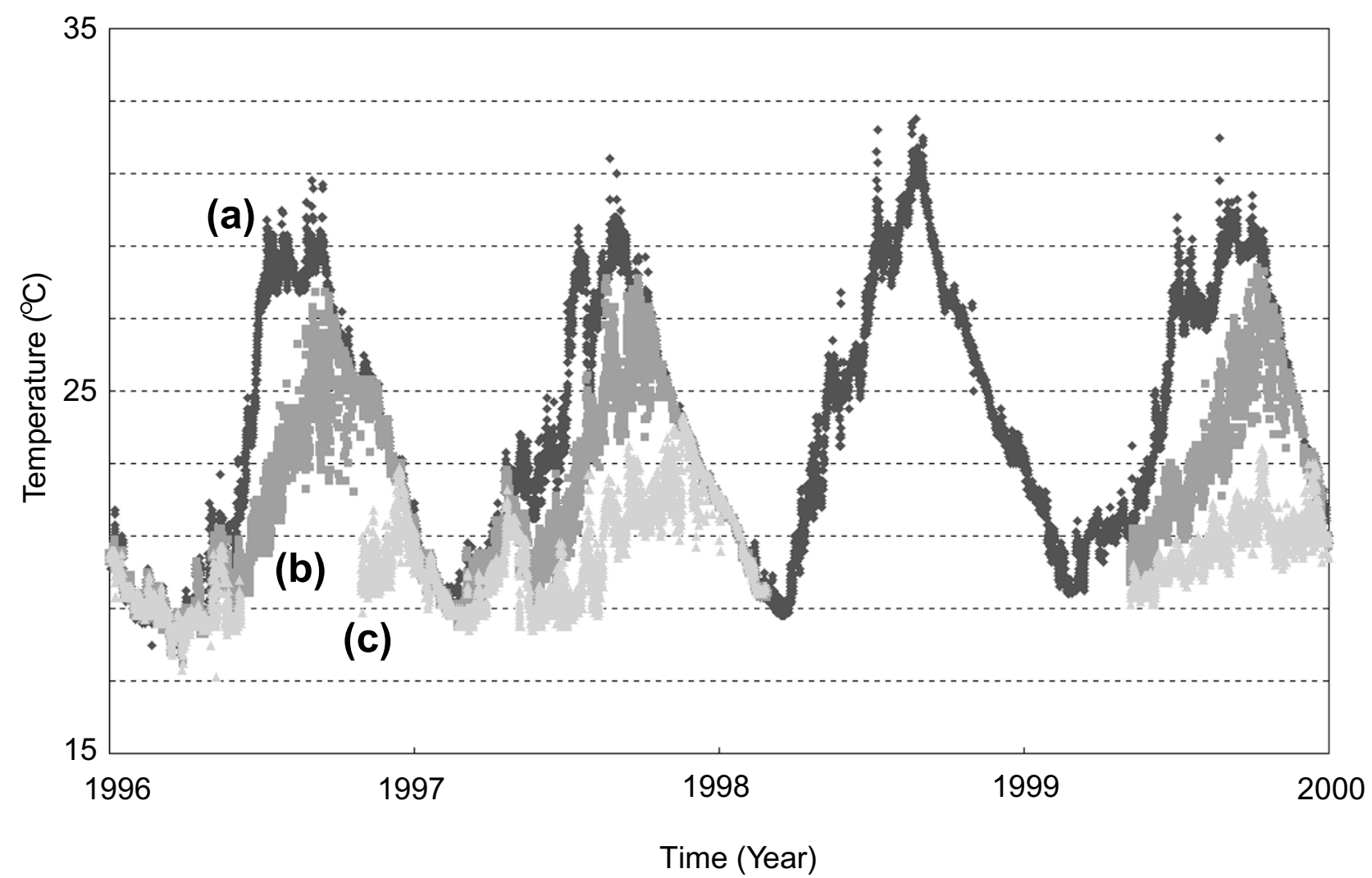

Fig. 5. Temperatures from January 1996 to December 1999 obtained by an ocean data buoy at latitude $29.0^{\circ} \mathrm{N}$ and longitude $135.0^{\circ} \mathrm{E}$, off south coast of Japan, of the Japan Meteorological Agency (JMA). Marks (a), (b), and (c) indicate temperatures with depths at 2, 50, and 100 m, respectively.

$3.7 \mathrm{~km} / \mathrm{h}$ ) and measure travel times at every 5 seconds, the spatial interval of observation stations becomes $5 \mathrm{~m}$ as assumed in this study.

The sound speed profile in Fig. 4(a) is calculated from the data obtained by Conductivity Temperature Depth profiler (CTD) at an experimental observation in the Suruga bay on January 16, 2001. Del Grosso (1974) gives an equation about sound speed $C_{S T P}$ in $\mathrm{m} / \mathrm{s}$ as;

$$
\begin{aligned}
C_{S T P}= & C_{000}+\Delta C_{T}+\Delta C_{S} \\
& +\Delta C_{P}+\Delta C_{S T P}
\end{aligned}
$$

where

$$
\begin{aligned}
C_{000}= & 1402.392, \\
\Delta C_{T}= & .01109398873 \times T \\
& -5.50946843172 \times 10^{-2} T^{2} \\
& +2.21535969240 \times 10^{-4} T^{3}, \\
\Delta C_{S}= & .32952290781 \times S \\
& +1.28955756844 \times 10^{-4} S^{2}, \\
\Delta C_{P}=1.56059257041 \times 10^{-1} P & +2.44998688441 \times 10^{-5} P^{2} \\
& -8.83392332513 \times 10^{-9} P^{3}, \\
\Delta C_{S T P}= & 1.27562783426 \times 10^{-2} T S \\
& +6.35191613389 \times 10^{-3} T P \\
& +2.65484716608 \times 10^{-8} T^{2} P^{2}
\end{aligned}
$$

$$
\begin{aligned}
& -1.59349479045 \times 10^{-6} T P^{2} \\
& +5.22116437235 \times 10^{-10} T P^{3} \\
& -4.38031096213 \times 10^{-7} T^{3} P \\
& -1.61674495909 \times 10^{-9} S^{2} P^{2} \\
& +9.68403156410 \times 10^{-5} T^{2} S \\
& +4.85639620015 \times 10^{-6} T S^{2} P \\
& -3.40597039004 \times 10^{-4} T S P,
\end{aligned}
$$

and where $T=$ temperature in degrees Celsius, $S=$ salinity in parts per thousand, and $P=$ pressure in kilograms per square centimeter. By using Eq. (1), we calculate the velocity structure in Fig. 4(a) from the CTD data, and also those in Figs. 4(b) and (c).

Sound speed structures in Figs. 4(b) and (c) are derived from that in Fig. 4(a) as follows. First, we assume the sound speed structure in Fig. 4(a) to be that with the lowest water temperature in the sea both throughout the day and the seasons. Figure 4(b) is a sound speed profile with highest temperatures in the day in comparison with that in Fig. 4(a). Figure 4(c) is a synthetic sound speed profile in the summer morning. From Eq. (1), sound speed is most sensitive to temperature changes. It takes several hours to measure acoustic distances by using this system, so it is necessary to evaluate observation errors due to internal waves (e.g., Spiess et al., 1998) and daily changes of sound speed structures as well as seasonal ones. Sound speeds in Figs. 4(b) and 4(c) have temperature anomalies as listed in Table 1 with respect to 
Table 1. Temperature anomalies of the sound speed structures in Figs. 4(b) and (c) with respect to that in Fig. 4(a).

\begin{tabular}{ccc}
\hline & \multicolumn{2}{c}{ Temperature Anomalies $\left({ }^{\circ} \mathrm{C}\right)$} \\
Depth $(\mathrm{m})$ & Fig. 4b & Fig. 4c \\
\hline $0-10$ & +1.5 & +10.0 \\
20 & +1.2 & +9.0 \\
30 & +1.2 & +8.0 \\
50 & +0.9 & +6.0 \\
75 & +0.7 & +4.5 \\
100 & +0.5 & +3.5 \\
125 & +0.3 & +2.8 \\
150 & +0.1 & +2.2 \\
175 & - & +1.5 \\
200 & - & +1.0 \\
225 & - & +0.7 \\
250 & - & +0.4 \\
275 & - & +0.2 \\
300 & - & +0.1 \\
\hline
\end{tabular}

that in Fig. 4(a). Daily and seasonal changes of sound speed structures are estimated based on temperature data from an ocean data buoy at latitude $29.0^{\circ} \mathrm{N}$ and longitude $135.0^{\circ} \mathrm{E}$, off south coast of Japan (see Fig. 5), of the Japan Meteorological Agency (JMA). To estimate daily and seasonal temperature changes for simulations in this study, it is necessary to use data at stations where observations have been carried out for at least several years with sampling at every a few hours. Before 1999, JMA had been observing temperatures every 3 hours in the sea at depths with 2, 50, and $100 \mathrm{~m}$ by ocean buoys, so it is valid to estimate temporal changes of temperatures in the sea by these data.

\section{Results}

\subsection{Signal recognition}

Table 2 shows the coefficients of cross correlations between the up-chirp wave and various waves with noises. We can see that if the $\mathrm{S} / \mathrm{N}$ ratio is larger than 0.4 , arrival times of up-chirp waves can be obtained precisely within the uncertainty of $0.027 \mathrm{~ms}(37.5-\mathrm{kHz})$ and the coefficients are larger than 0.40 . Basing on these results, we have adjusted the observation system so that it calculates round-trip times only if the coefficients are larger than 0.40 , and the $\mathrm{S} / \mathrm{N}$ ratio has actually been much larger than 0.4 during observation sessions in the sea (see Fig. 6). Therefore, we can conclude that we are able to obtain precise arrival times of up-chirp signals, or round-trip times within the uncertainty of $0.027 \mathrm{~ms}$. As a result, we can observe distances between the onboard sta-

Table 2. Coefficients of cross correlations between the up-chirp wave and various waves with noises.

\begin{tabular}{|c|c|c|c|c|}
\hline Wave Forms & $\begin{array}{c}\text { Frequency } \\
\text { Range }(\mathrm{kHz})\end{array}$ & $\begin{array}{l}\text { S/N } \\
\text { Ratio }\end{array}$ & $\begin{array}{c}\text { Coefficients of } \\
\text { Cross Correlations }\end{array}$ & $\begin{array}{c}\text { Precision of } \\
\text { Arrival Time* }\end{array}$ \\
\hline Noise & - & - & 0.35 & $x$ \\
\hline \multirow[t]{7}{*}{ Up-chirp Wave } & \multirow[t]{7}{*}{$8-12$} & 0.1 & 0.37 & $x$ \\
\hline & & 0.2 & 0.37 & $x$ \\
\hline & & 0.3 & 0.39 & $x$ \\
\hline & & 0.4 & 0.44 & O \\
\hline & & 0.5 & 0.56 & O \\
\hline & & 0.7 & 0.72 & $\bigcirc$ \\
\hline & & 1.0 & 0.85 & $\bigcirc$ \\
\hline Down-chirp Wave & $12-8$ & 1.0 & 0.27 & $x$ \\
\hline \multirow[t]{3}{*}{ Sine Wave } & 8 & 1.0 & 0.36 & $x$ \\
\hline & 10 & 1.0 & 0.36 & $x$ \\
\hline & 12 & 1.0 & 0.36 & $x$ \\
\hline
\end{tabular}

*.symbols: C, Good; ×. Poor. tion (whose position changes during the observation) and the seafloor station within 4.0-cm error if we assume the sound speed in the sea as $1.5 \times 10^{3} \mathrm{~m} / \mathrm{s}$. Since coefficients for a down-chirp wave and sinusoidal waves are much smaller than 0.40 (see Table 2), there is no possibility that the system detects reflected down-chirp waves that have been transmitted from the onboard station or sinusoidal waves generated by other sources (e.g., an echo sounder) as up-chirp signals from the seafloor station.

\subsection{Azimuthal coverage of observation lines}

Both accurate spatio-temporal sound speed measurements and uniform azimuthal coverage of onboard observation points around the single seafloor station are required for the highest accuracy in positioning the seafloor station. Under actual operational conditions, however, it is often difficult to obtain sufficient azimuthal coverage and spatio-temporal measurements of sound speed. In the following we first investigate the sensitivity of the solution to the azimuthal coverage and then to inaccurate spatio-temporal sound speed measurements.

To investigate effects due to azimuthal coverage of observation lines, we carry out some simulations. We adopt the sound speed structure shown in Fig. 4(a) for the simulation. We compute the sum of squared differences between "observed" travel times and calculated ones assuming that the sound speed is constant both spatially and temporally, or independently of depth. This corresponds to a situation that we cannot or do not observe the sound speed by CTD etc. and analyze data assuming the sound speed to be uniform in depth. We determine the position of the seafloor station and the sound speed with the least squared sum of residuals. Figure 7 shows the result when we can obtain travel-time data at 4,411 onboard points. The position of the seafloor station is determined at $(0.00,0.00,-1500.09) \mathrm{m}$. The determined position is accurate in lateral but have a bias about 10 $\mathrm{cm}$ in vertical. This is because residuals are forced to errors of sound speed estimation in the analysis with assuming the sound speed to be uniform from the surface to the seafloor. If we can spare much time to the observation, it is possible to make a lot of acoustic ranging as in Fig. 7. But when the

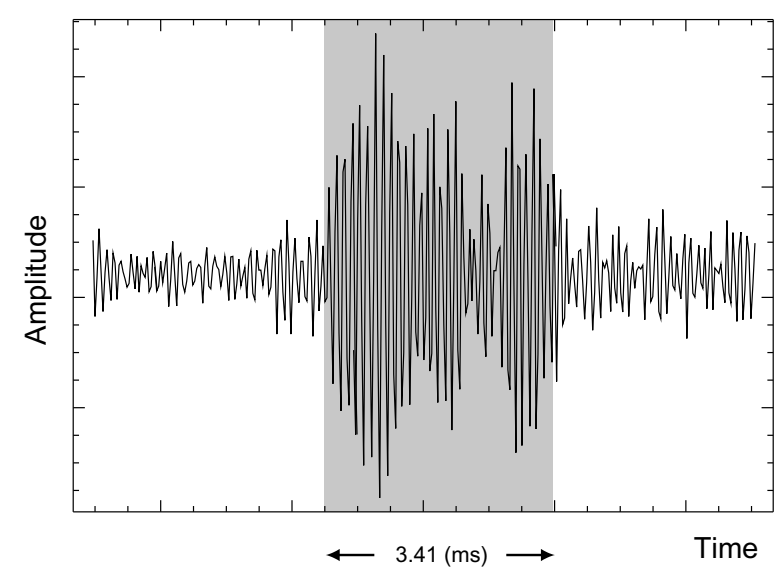

Fig. 6. An example of the up-chirp waveform from the seafloor station. This waveform was obtained at an experimental observation on October 23, 2000. The up-chirp signal is shaded in the received waveform. The $\mathrm{S} / \mathrm{N}$ ratio is much greater than 0.4 . 

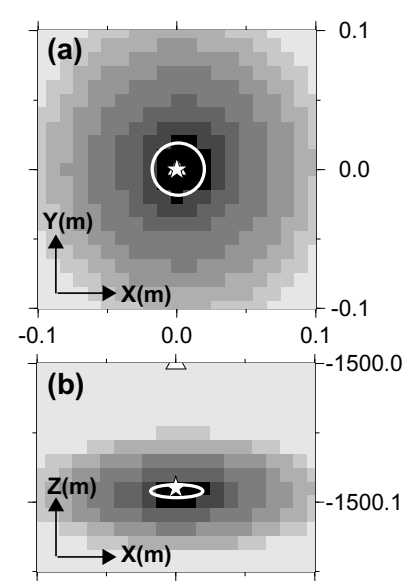
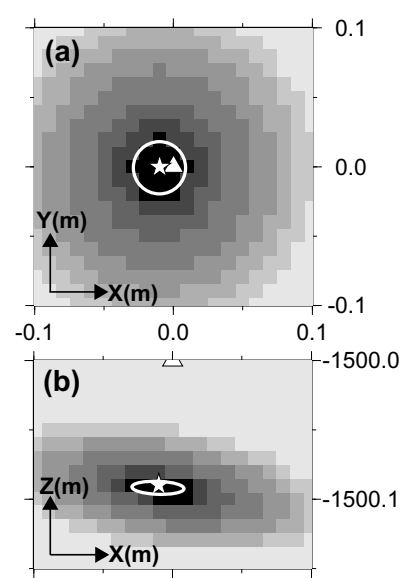

(c)

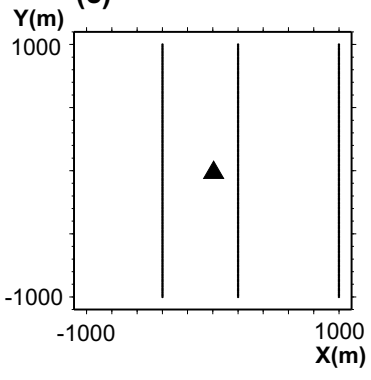

Difference of Standard Deviation

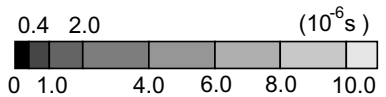

Fig. 7. The (a) $X Y$ and (b) $X Z$ cross sections of the distribution of the sum of squared travel-time residuals analyzed by assuming that the sound speed in the sea is uniform from the surface to the seafloor when it is actually that in Fig. 4(a) and we can observe travel times at all 4,411 points ranging from $-1,000 \mathrm{~m}$ to $1,000 \mathrm{~m}$ in both $X$ and $Y$ directions with every $200 \mathrm{~m}$ and $5 \mathrm{~m}$ along $X$ and $Y$ axes, respectively (see (c)). The star and triangle point out the determined and "true" positions of seafloor stations. White ellipses show confidence intervals in 95\% level. Colors in (a) and (b) indicate the differences between standard deviations of travel-time residuals and their minimum value in $10^{-6} \mathrm{~s}$. The position of the seafloor station is determined at $(0.00,0.00,-1500.09) \mathrm{m}$. The confidence intervals in $95 \%$ level are 4,4 , and $1 \mathrm{~cm}$ in $X, Y$, and $Z$ directions, respectively.
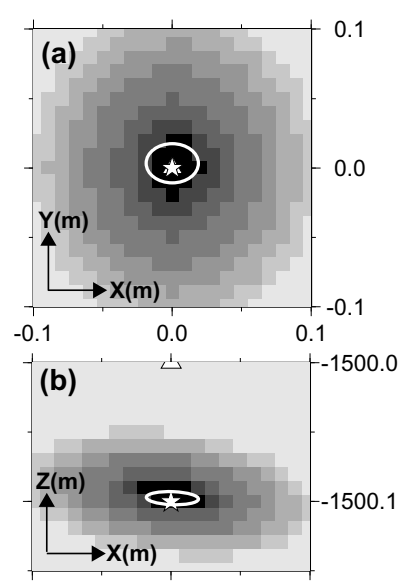

(c)

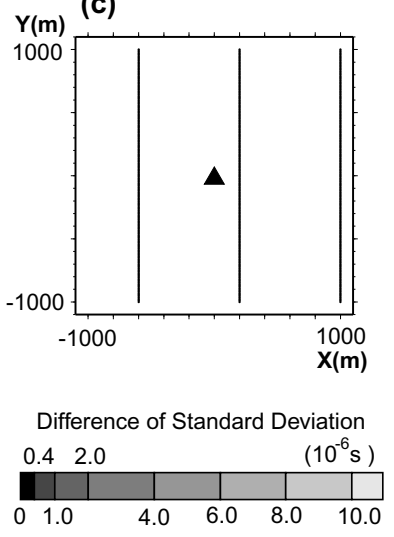

Fig. 8. The (a) $X Y$ and (b) $X Z$ cross sections of the distribution of the sum of squared travel-time residuals when we can observe travel times at onboard points with $X=-600,200$, and 1,000 m (see (c)). Symbols and colors are the same as in Fig. 7. The position of the seafloor station is determined at $(0.00,0.00,-1500.10) \mathrm{m}$. The confidence intervals in $95 \%$ level are 4,3 , and $1 \mathrm{~cm}$ in $X, Y$, and $Z$ directions, respectively.

observation is limited in time, including that we have to go to a station near the Nankai trough from Japan, make acoustic measurements, and return in one day, we can obtain data at a few observation lines at most. Figure 8 shows the result when we can obtain travel-time data at 1,203 onboard points with $X=-600,200$, and $1,000 \mathrm{~m}$. The position of the seafloor station is determined at $(0.00,0.00,-1500.10) \mathrm{m}$. The position of the seafloor station can be accurately determined in lateral despite the asymmetric distribution of observation lines with respect to the seafloor station. Figure 9 shows the result for travel-time data at onboard points with

Fig. 9. The (a) $X Y$ and (b) $X Z$ cross sections of the distribution of the sum of squared travel-time residuals when we can observe travel times at onboard points with $X=-400,200$, and 1,000 m (see (c)). Symbols and colors are the same as in Fig. 7. The position of the seafloor station is determined at $(-0.01,0.00,-1500.09) \mathrm{m}$. The confidence intervals in $95 \%$ level are 4,4 , and $1 \mathrm{~cm}$ in $X, Y$, and $Z$ directions, respectively.
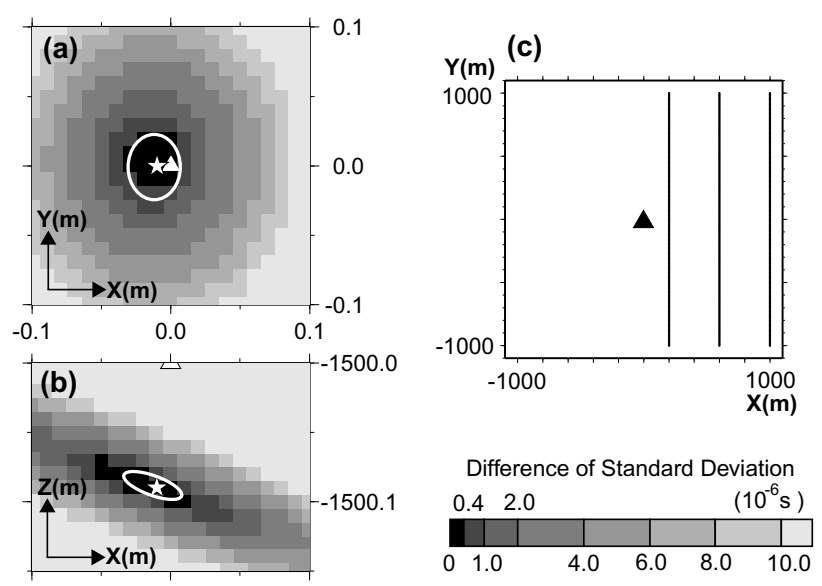

Fig. 10. The (a) $X Y$ and (b) $X Z$ cross sections of the distribution of the sum of squared travel-time residuals when we can observe travel times at onboard points with $X=200,600$, and 1,000 m (see (c)). Symbols and colors are the same as in Fig. 7. The position of the seafloor station is determined at $(-0.01,0.00,-1500.09) \mathrm{m}$. The confidence intervals in $95 \%$ level are 4,5 , and $3 \mathrm{~cm}$ in $X, Y$, and $Z$ directions, respectively.

$X=-400,200$, and $1,000 \mathrm{~m}$. The position of the seafloor station is determined at $(-0.01,0.00,-1500.09) \mathrm{m}$. The position of the seafloor station can be determined within afew-cm discrepancy in lateral despite the asymmetric distribution of observation lines with respect to the seafloor station nor irregular intervals between observation lines. Figure 10 shows the result for travel-time data at onboard points with $X=200,600$, and $1,000 \mathrm{~m}$. The position of the seafloor station is determined at $(-0.01,0.00,-1500.09) \mathrm{m}$. Although confidence intervals in $95 \%$ level are a little larger, the position of the seafloor station can be determined within a-few$\mathrm{cm}$ discrepancy in lateral despite the one-sided distribution of observation points. These results insist that the discrepancy of the determined position of the seafloor station due to the azimuthal coverage of observation lines can be suppressed within a few $\mathrm{cm}$ in lateral. This reveals that the so- 
lution is insensitive to the azimuthal coverage of observation points.

In these simulations, however, it is assumed that the sound speed never changes both spatially and temporally. Of course, in actual observations in the sea, this is not the case. In following subsections, we will investigate the sensitivities of solutions to inaccurate spatio-temporal sound speed measurements.

\subsection{Seasonal changes of sound speed}

The observation of seafloor crustal deformation would be carried out throughout the year, so we also have to investigate observation errors due to seasonal changes of the sound speed structure. We assume that the sound speed structure in the sea is that in Fig. 4(c) and analyze with the same method as in the Subsection 4.2. Fig. 11 shows the result for travel-time data at onboard points with $X=-600,200$, and $1,000 \mathrm{~m}$. The distribution of observation lines is exactly the same as in Fig. 8. The position of the seafloor station is determined at $(0.01,0.00,-1500.13) \mathrm{m}$. Results in Figs. 8 and 11 reveal that seasonal changes of the velocity structure of the sea water affect little to the determination of the horizontal position of the seafloor station. This is because residuals are forced to determination of sound speed when we analyze data with assuming that sound speed is spatially constant from the surface to the seafloor.

\subsection{Daily changes of sound speed}

If we can observe spatio-temporal changes of the sound speed in the sea very accurately, observation errors due to daily changes of the sound speed can be eliminated. As a matter of fact, it is impossible. The sound speed structure in the sea varies in space and time. The shallower sea water varies with daily changes in temperature and currents, etc. In this subsection, we investigate the errors due to daily changes of the temperature in the sea. Referring to Eq. (1), the sound speed is the most sensitive to temperature changes, so errors due to daily changes in the sound speed can be
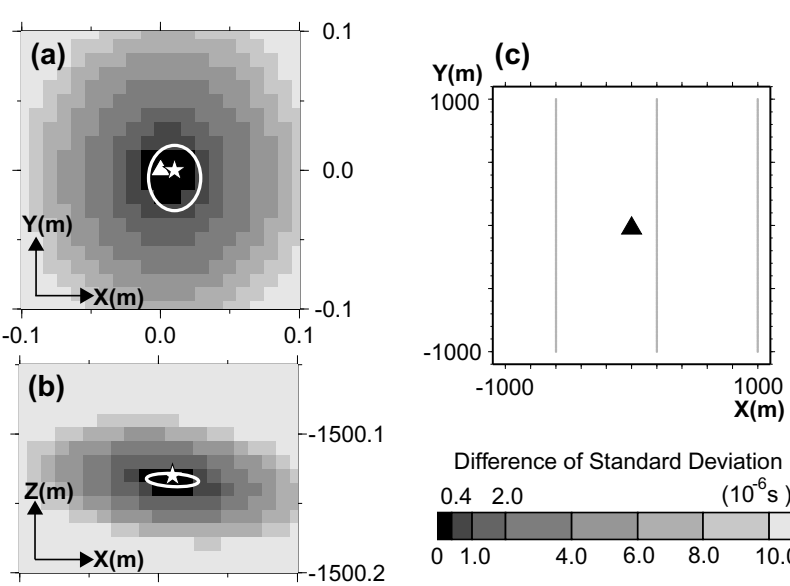

Difference of Standard Deviation

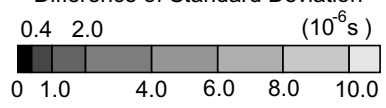

Fig. 11. The (a) $X Y$ and (b) $X Z$ cross sections of the distribution of the sum of squared travel-time residuals. The distribution of observation lines is the same as in Fig. 8 but we assume that the sound speed in the sea is uniform from the surface to the seafloor when it is actually that in Fig. 4(c) (see (c)). Symbols and colors are the same as in Fig. 7. The position of the seafloor station is determined at $(0.01,0.00,-1500.13) \mathrm{m}$. The confidence intervals in $95 \%$ level are 4,5 , and $1 \mathrm{~cm}$ in $X, Y$, and $Z$ directions, respectively. investigated by studying effects of sound speed changes due to daily changes in temperature. Figure 12 shows the result for travel-time data at onboard stations with $X=-400,200$, and $1,000 \mathrm{~m}$. The distribution of observation lines is exactly the same as in Fig. 9. But in this simulation we use one-way travel times calculated by using the sound speed structures in Figs. 4(a) and (b) as one-way "observed" data of observation lines with $X=200 \mathrm{~m}$ and with $X=-400$ and $1,000 \mathrm{~m}$, respectively. This assumes that observations are taken place along lines with $X=200 \mathrm{~m}$ in the morning and with $X=$ -400 and $1,000 \mathrm{~m}$ around the noon. In the same way as in Subsections 4.2 and 4.3, we analyze data assuming the sound speed to be uniform from the surface to the seafloor and also temporally constant, which corresponds to a situation that we cannot or do not observe the sound speed by CTD etc. The position of the seafloor station is determined at $(-0.25,0.00$, $-1500.96) \mathrm{m}$. The confidence interval in lateral is $5 \mathrm{~cm}$ in $95 \%$ level. Both the discrepancy in lateral and the confidence interval are larger than a-few-cm level. This result insists that if we cannot, or do not, obtain the sound speed structure in the sea, there is the potential that the discrepancy between the determined position of the seafloor station and the "true" one becomes larger than $20 \mathrm{~cm}$. Results in Figs. 9 and 12 point out that daily changes of the sound speed structure in the sea cause serious errors in seafloor geodesy if we analyze travel-time data with assuming that the sound speed structure is temporally constant.

\subsection{Sound speed changes due to the internal wave}

Results in the last few subsections reveal that the position of the seafloor station cannot be determined within a-few$\mathrm{cm}$ discrepancy with respect to the true position if we cannot obtain the precise sound speed in the sea or we analyze data with disregarding the effects of its temporal changes. These errors can be resolved if we observe precise sound speed profile and analyze travel-time data with taking the profile into account. One of the ways we obtain it precisely will be
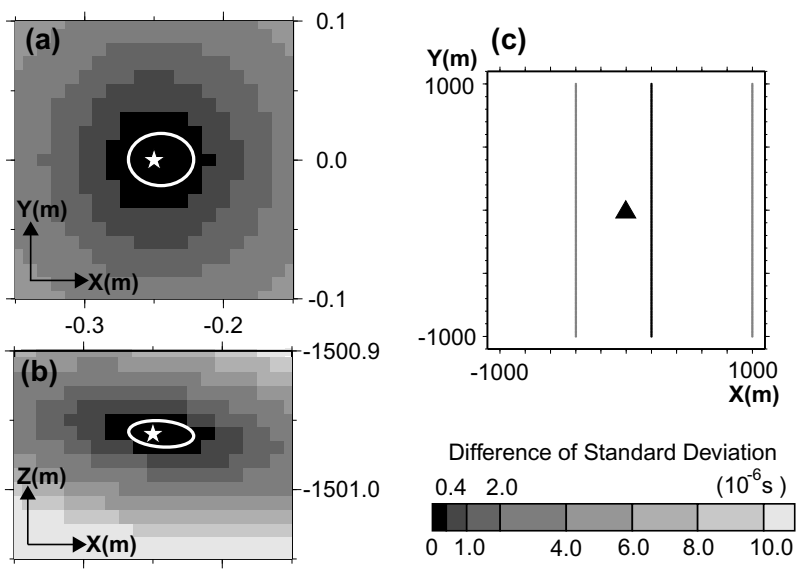

Fig. 12. The (a) $X Y$ and (b) $X Z$ cross sections of the distribution of the sum of squared travel-time residuals. The distribution of onboard points is the same as in Fig. 9 but we assume that the sound speed structure in the sea is uniform from the surface to the seafloor when the structures are actually those in Figs. 4(a) and (b) with $X=200 \mathrm{~m}$ and with $X=-400$ and $1,000 \mathrm{~m}$, respectively (see (c)). Symbols and colors are the same as in Fig. 7. The position of the seafloor station is determined at $(-0.25$, $0.00,-1500.96) \mathrm{m}$. The confidence intervals in $95 \%$ level are 5, 4, and $2 \mathrm{~cm}$ in $X, Y$, and $Z$ directions, respectively. 
to observe temperatures and salinities in the sea by CTD as frequently as possible during observations. In this and the next subsection we are going to investigate errors which are hard to be conquered in the observation and the analysis.

Spiess et al. (1998) pointed out that sound speed changes occur with period as short as 20 minutes and cause equivalent effects of about $20 \mathrm{~cm}$ in the acoustic distance. They attribute them to the internal wave. An observation of temperatures and salinities in the sea by CTD down to $1,500 \mathrm{~m}$ takes more than an hour, so it is hard to eliminate errors due to the internal wave entirely and its effect should be investigated. Referring to Spiess et al. (1998), we assume that we can only obtain the sound speed averaged over the time required to CTD observation, and the sound speed change occurs because of the internal wave with periods of $1,000 \mathrm{~s}$ and causes fluctuations with a maximum amplitude of $0.080 \mathrm{~ms}$ on travel-time data, which is equivalent to $\pm 12 \mathrm{~cm}$. If we assume that the current speed is $1.0 \mathrm{~m} / \mathrm{s}$ (about 2.0 knots), we can write this effect $\Delta T(Y)$ as;

$$
\Delta T(Y)=0.080 \sin \left(\frac{2 \pi}{1000} Y\right)
$$

where $\Delta T(Y)$ is in milliseconds.

We assume that we observe travel-time data and temperature profiles in the sea at onboard points with $X=-400$, 200 , and 1,000 $\mathrm{m}$ but cannot observe temporal fluctuations due to the internal wave which are written as (2). Figure 13 shows the result at this situation. The position of the seafloor station is determined at $(-0.02,0.09,-1499.97) \mathrm{m}$. This result insists that the internal wave will cause about a $10 \mathrm{~cm}$ error in lateral positioning of a single seafloor station.

4.6 Accuracy of temperature data by CTD observation

Generally, CTD has accuracy with $\pm 0.01^{\circ} \mathrm{C}$ in temperature. The accuracy with $\pm 0.01^{\circ} \mathrm{C}$ is very high, but referring to Eq. (1), this infinitesimal observation error in temperature may affect in determining the position of the seafloor station.
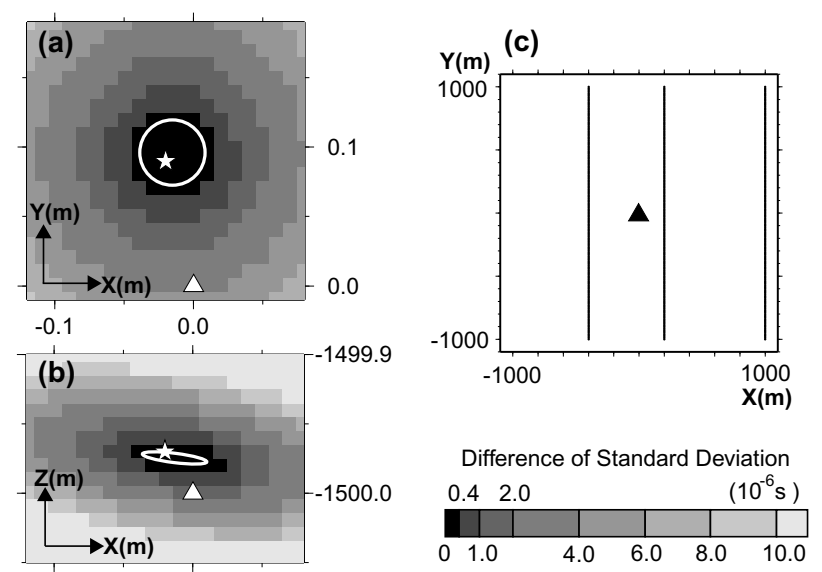

Fig. 13. The (a) $X Y$ and (b) $X Z$ cross sections of the distribution of the sum of squared travel-time residuals when we observe travel times and temperature profiles in the sea at onboard points with $X=-400,200$, and 1,000 $\mathrm{m}$ but cannot observe temporal fluctuations due to the internal wave which are written as the equation (2). Symbols and colors are the same as in Fig. 7. The position of the seafloor station is determined at $(-0.02,0.09,-1499.97) \mathrm{m}$. The confidence intervals in $95 \%$ level are 5 , 5 , and $1 \mathrm{~cm}$ in $X, Y$, and $Z$ directions, respectively.
We assume that we observe travel-time data and temperature profiles in the sea at onboard points with $X=-400$, 200 , and 1,000 $\mathrm{m}$ but the profiles have systematic errors associated with the accuracy of the CTD measurements. To investigate their effects, we suppose that observed temperature profiles with $X=-400$ and $1,000 \mathrm{~m}$ and $X=200 \mathrm{~m}$ have errors with $\pm 0.01^{\circ} \mathrm{C}$, respectively. Figure 14 shows the result at this situation. The position of the seafloor station is determined at $(-0.03,0.00,-1499.99) \mathrm{m}$. Figure 15 shows the result for the case that the distribution of observation lines is the same as in Fig. 14 and observed temperature profiles, but they include systematic errors with $\pm 0.01^{\circ} \mathrm{C}$ in $X=200$
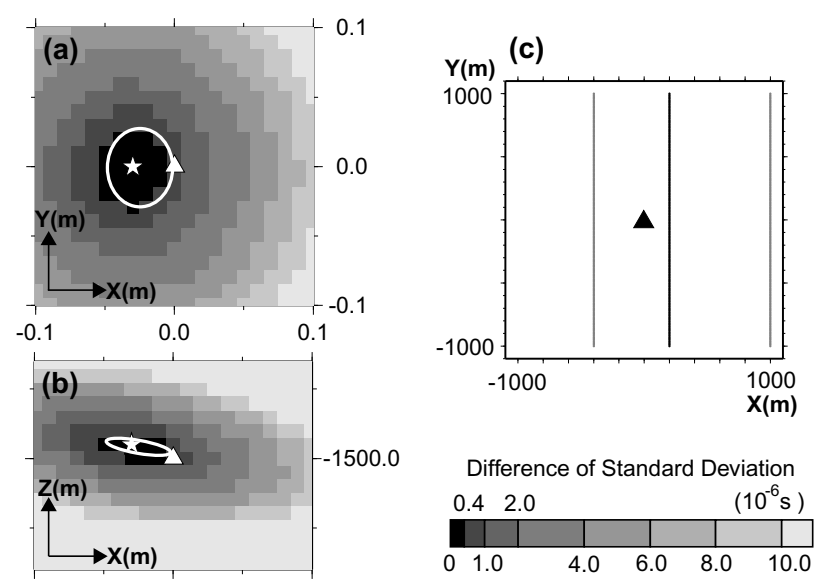

Fig. 14. The (a) $X Y$ and (b) $X Z$ cross sections of the distribution of the sum of squared travel-time residuals when we observe travel times and temperature profiles in the sea at observation lines with $X=-400$, 200 , and $1,000 \mathrm{~m}$ but observed temperature profiles with $X=200 \mathrm{~m}$ and $X=-400$ and $1,000 \mathrm{~m}$ have errors with $-0.01^{\circ} \mathrm{C}$ and $+0.01^{\circ} \mathrm{C}$, respectively. Symbols and colors are the same as in Fig. 7. The position of the seafloor station is determined at $(-0.03,0.00,-1499.99) \mathrm{m}$. The confidence intervals in $95 \%$ level are 5,6 , and $2 \mathrm{~cm}$ in $X, Y$, and $Z$ directions, respectively.
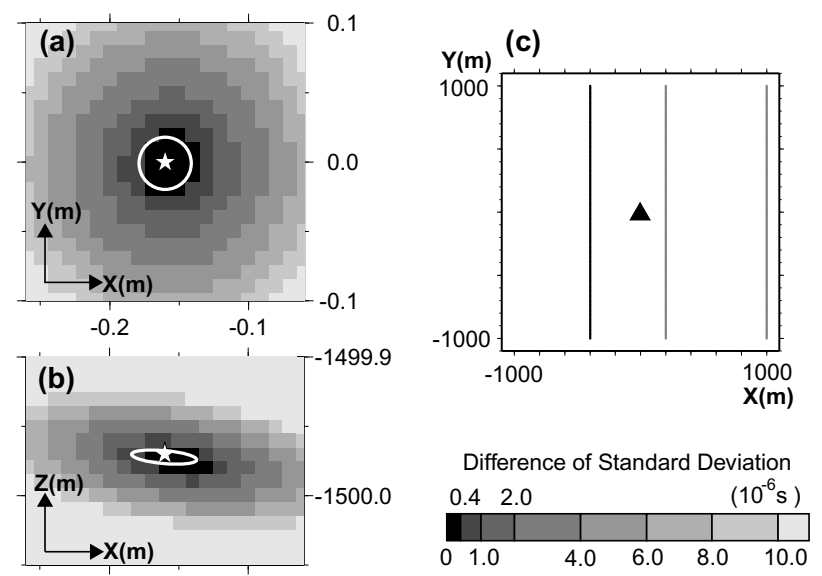

Fig. 15. The (a) $X Y$ and (b) $X Z$ cross sections of the distribution of the sum of squared travel-time residuals when we observe travel times and temperature profiles at observation lines the same as Fig. 13 but observed temperature profiles with $X=-400 \mathrm{~m}$ and $X=200$ and $1,000 \mathrm{~m}$ have errors with $-0.01^{\circ} \mathrm{C}$ and $+0.01^{\circ} \mathrm{C}$, respectively. Symbols and colors are the same as in Fig. 7. The position of the seafloor station is determined at $(-0.16,0.00,-1499.97) \mathrm{m}$. The confidence intervals in $95 \%$ level are 4 , 4 , and $1 \mathrm{~cm}$ in $X, Y$, and $Z$ directions, respectively. 
and $1,000 \mathrm{~m}$ and $X=-400 \mathrm{~m}$, respectively. In this case, the position of the seafloor station is determined at $(-0.16,0.00$, $-1499.97) \mathrm{m}$. It is, however, a extreme case that simulated in Fig. 15, so less errors due to the accuracy of temperature in CTD observation would be included at actual observation in the sea. Results in Section 4 imply that it is possible that we can suppress observation errors due to acoustic ranging with about $18 \mathrm{~cm}\left(=\sqrt{10^{2}+16^{2}}\right.$; referring to results in subsections 4.5 and 4.6) if we observe sound speed structures with each observation line by CTD observation.

\section{Discussion and Conclusions}

We have performed numerical simulations to evaluate how much measurement errors may be contained in acoustic measurements using the system adopted in Tadokoro et al. (2001) and to investigate analysis errors of the determined position of a single seafloor station with and without observations of the sound speed structures in the sea by CTD. Since we have revealed that the chirp waves are usually noise-proof and their arrival times are detected precisely, results in this paper generally apply to the accuracy of the determined position of a seafloor transponder for other observation systems of seafloor geodesy using other acoustic signals, including M-sequence etc. (e.g., Obana et al., 2000; Asada and Yabuki, 2001), only if their arrival times are detected precisely. We have found that we can suppress errors associated with the acoustic positioning within about $18 \mathrm{~cm}$ if we obtain precise sound speed with each observation line by CTD observation etc. This uncertainty is obtained for one single seafloor station. If we deploy three or more nearby seafloor stations as a unit (Spiess et al., 1998; Asada and Yabuki, 2001) and collect ranges from the vessel at the center of the array to cancel the effect of temporally coherent sound speed variations, we could detect the seafloor crustal deformation with centimeter-level repeatability. If we install plural number of seafloor stations as a unit, we must distinguish signals from each station. Seafloor stations of the system adopted in Tadokoro et al. (2001) send three same up-chirp signals with different intervals between the signals in each station, so the system will have no difficulty in organizing the units and detect movements of their centers.

The curvature of the earth is neglected for simplicity in this study. The position of the vessel is determined by kinematic GPS based on the World Geodetic System in actual observation sessions, so the validity of simulations in this study does not be lost. However, in analyzing data with assuming that the sound speed in the sea have a layered structure, we have to suppose layers based on the geodetic ellipsoid.

This study reveals that acoustic part of the system may cause errors less than about $18 \mathrm{~cm}$ in determining the position of the seafloor station. Colombo et al. (2001) reported that the position of the observation vessel can be determined within $10 \mathrm{~cm}$ accuracy by kinematic GPS positioning. As a result, the position of the seafloor station can be determined within $28 \mathrm{~cm}$ accuracy by the system (see Fig. 16). But Sato et al. (2001) reported that the accuracy of the kinematic GPS positioning depends on the baseline length between rover and fixed receivers (in Fig. 1, they correspond to the observation vessel and GPS base station, respectively). We will give the detailed discussions about the accuracy of the kinematic

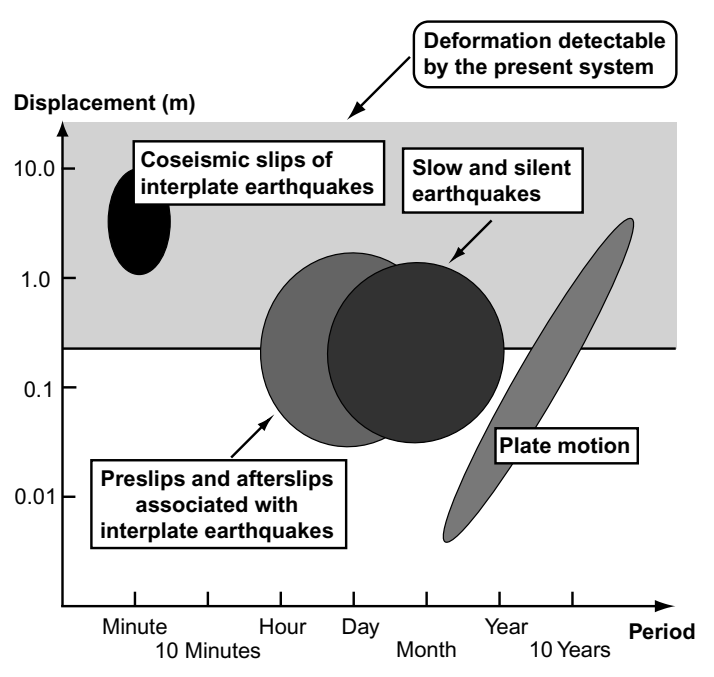

Fig. 16. Schematic illustration of deformation scales with various types of crustal activities and limits of them detectable by the system (as of December, 2001).

GPS positioning somewhere.

In this simulation, we have assumed that the sound speed in the sea has a layered structure. But we would not be able to neglect the lateral heterogeneity of temperature in the sea in actual observations. Although we obtain the sound speed structures by CTD observation, they are vertical profiles beneath the vessel. On the other hand, acoustic paths from seafloor stations to the onboard station are not generally vertical. Moreover, when we observe the seafloor crustal deformation at areas with prominent ocean currents, including around Nankai trough across the Japan Current, spatiotemporal heterogeneity of temperature in the sea may be present and will affect acoustic measurements. We plan to examine the extent of heterogeneities and develop methods for their reduction through continuous observations.

Large interplate earthquakes have repeatedly occurred along the Nankai trough with an interval of from 100 to over 200 years (Ando, 1975). Coseismic slips of 1944 Tonankai and 1946 Nankai earthquakes exceeded $1 \mathrm{~m}$ in most of the slipped area (e.g., Kato and Ando, 1997; Sagiya and Thatcher, 1999; Tanioka and Satake, 2001a, b). If we can expect that the next great interplate earthquake along the Nankai trough will have coseismic slip with over $1 \mathrm{~m}$, it will be sufficiently detectable. Furthermore, seafloor geodetic data collected by the system for the seafloor crustal deformation will play an important role for estimating coseismic slip distribution of interplate earthquakes, since that estimated from inversion of tsunami waveforms have uncertainty with a few decimeter (Tanioka and Satake, 2001a).

Plafker (1972) observed about $8 \mathrm{~m}$ of up-lift displacement on Montegue Island which was inferred to have occurred during the 1964 Alaskan earthquake. It suggests that splay faults may have slipped at the earthquake. Cummins et al. (2001) reported that slips on splay faults may have occurred on a particular segment of the Nankai trough offshore western Shikoku, Japan during the earthquakes of 1707 and 1946. They also suggested that such slip may cause a significant effect on stress reduction on the portion of the megathrust seaward of the splay fault and this stress reduction could 
lengthen the recurrence time for future earthquake slip to occur there. Observations of the seafloor crustal deformation will provide critical data in understanding the spatial distribution of slips associated with large interplate earthquakes and their mechanisms.

Recently, slow slip events around subduction zones are reported (e.g., Heki et al., 1997; Hirose et al., 1999; Dragert et al., 2001; Ozawa et al., 2001a, b; Thatcher, 2001). These events could be recognized owing to the precise monitoring of the crustal deformation by GPS. These events may have been taking place in other subduction zones, including off Kii peninsula and off Shikoku along the Nankai trough. But these areas have a little close GPS stations and poor azimuthal coverage, so such events, if occurring, may not be detected with GPS data. On the other hand, Kawasaki et al. (1995) found the 1992 Sanriku-Oki ultra-slow earthquake by high-resolution crustal strain observations. They also reported that horizontal displacements on land predicted by their fault model of the earthquake are about $0.5 \mathrm{~cm}$. Therefore, large uncertainties can be included in quantitative evaluations of slips associated with off-shore slow and silent events which are detected from only on-land deformation data, including GPS and VLBI observations. The observation system for the seafloor crustal deformation will play an important role in monitoring seafloor motion in these areas.

The interface between seafloor stations and the ocean bottom will be basic to stable observations of seafloor crustal deformation. In order to monitor motions of lithosphere, or oceanic plate, it is necessary to fix seafloor stations well on the seafloor; otherwise the stations would move independently of the seafloor movement when strong motions strike them. As of 2002, seafloor stations are installed by free fall from the sea surface. We must consider how to fix them on the seafloor for further stable observations.

In the future, the dense installation of seafloor stations and the further development of analysis techniques for seafloor geodesy will provide us detailed and precise data of the seafloor crustal deformation. These data will give an important clue to understanding mechanisms of great interplate earthquakes and activities of submarine volcanoes, conditions of interplate couplings, and the post-seismic viscoelastic deformation associated with interplate earthquakes, etc. Therefore, we emphasize the importance of continuous observations with a nationwide geodetic observational network for seafloor crustal deformation.

Acknowledgments. The authors would like to thank C. D. Chadwell and A. Sengoku for reviewing the manuscript and their very useful comments and suggestions. The authors also thank $\mathrm{N}$. Matsuo, N. Hirano, and H. Katao for their technical support. Experimental observations in October 2000 and January 2001 were carried out by using the "Suruga Maru," which belongs to the Fisheries Experimental Station of Shizuoka Prefecture, Yaizu, Japan. Daily and seasonal changes of the sound speed in the sea were estimated on temperature data from an ocean data buoy at latitude $29.0^{\circ} \mathrm{N}$ and longitude $135.0^{\circ} \mathrm{E}$, off south coast of Japan, of the Japan Meteorological Agency. This work was partially supported by Grant-in-Aid for Scientific Research ((A)11691126, 2000) from the Ministry of Education, Culture, Sports, Science and Technology of Japan. T. Yamada is a Research Fellow of the Japan Society for the Promotion of Science.

\section{References}

Ando, M., Source mechanisms and tectonic significance of historical earthquakes along the Nankai trough, Japan, Tectonophysics, 27, 119-140, 1975.

Asada, A. and T. Yabuki, Progress in the long-term seafloor geodesy on the Kumano Trough, J. Geography, 110, 529-543, 2001 (in Japanese with English abstract).

Colombo, O. L., A. G. Evans, M. Ando, K. Tadokoro, K. Sato, and T. Yamada, Speeding up the estimation of floated ambiguities for subdecimeter kinematic positioning at sea, Proc. ION GPS 2001, Salt Lake City, U.S.A., 2001.

Cummins, P. R., T. Hori, and Y. Kaneda, Splay fault and megathrust earthquake slip in the Nankai Trough, Earth Planets Space, 53, 243-248, 2001.

Del Grosso, V. A., New equation for the speed of sound in natural waters (with comparisons to other equations), J. Acoust. Soc. Am., 56, 1084 1091, 1974.

Dragert, H., K. Wang, and T. James, A silent slip event on the deeper Cascadia subduction interface, Science, 292, 1525-1528, 2001.

Fujimoto, H., T. Kanazawa, and H. Murakami, Experiment on precise seafloor acoustic ranging-A promising result of observation-, J. Seismol. Soc. Jpn., Ser. 2, 48, 289-292, 1995 (in Japanese).

Greenewalt, D. and C. M. Gordon, Short-term variability in the bottom boundary layer of the deep ocean, J. Geophys. Res., 83, 4713-4716, 1978

Heki, K., S. Miyazaki, and H. Tsuji, Silent fault slip following an interplate thrust earthquake at the Japan Trench, Nature, 386, 595-598, 1997.

Hirose, H., K. Hirahara, F. Kimata, N. Fujii, and S. Miyazaki, A slow thrust slip event following the two 1996 Hyuganada earthquakes beneath the Bungo Channel, southwest Japan, Geophys. Res. Lett., 26, 3237-3240, 1999.

Ito, T., S. Yoshioka, and S. Miyazaki, Interplate coupling in southwest Japan deduced from inversion analysis of GPS data, Phys. Earth Planet. Inter. 115, 17-34, 1999 .

Kato, T. and M. Ando, Source mechanisms of the 1944 Tonankai and 1946 Nankaido earthquakes: Spatial heterogeneity of rise times, Geophys. Res. Lett., 24, 2055-2058, 1997.

Kawasaki, I., Y. Asai, Y. Tamura, T. Sagiya, N. Mikami, Y. Okada, M. Sakata, and M. Kasahara, The 1992 Sanriku-Oki, Japan, Ultra-Slow Earthquake, J. Phys. Earth, 43, 105-116, 1995.

Miyazaki, S. and Y. Hatanaka, Summary of the GPS Earth Observation Network in Japan being carried out by the Geographical Survey Institute, Meteorological Research Note, 192, 11-22, 1998 (in Japanese).

National Astronomical Observatory (ed.), Rika Nenpyo (Chronological Scientific Tables), pp. 636-637, Maruzen Co. Ltd., Tokyo, 2002.

Nishimura, S., M. Ando, and S. Miyazaki, Inter-plate coupling along the Nankai Trough and southeastward motion along southern part of Kyushu, J. Seismol. Soc. Jpn., Ser. 2, 52, 443-456, 1999 (in Japanese with English abstract).

Obana, K., H. Katao, and M. Ando, Seafloor positioning system with GPSacoustic link for crustal dynamics observation - a preliminary result from experiments in the sea-, Earth Planets Space, 52, 415-423, 2000.

Ozawa, S., T. Murakami, and T. Tada, Time-dependent inversion study of the slow thrust event in the Nankai trough subduction zone, southwestern Japan, J. Geophys. Res., 106, 787-802, 2001a.

Ozawa, S., T. Murakami, M. Kaidzu, T. Tada, T. Sagiya, H. Yarai, and T. Nishimura, Anomalous crustal deformation in the Tokai region in 2001 , Abstr. Seismol. Soc. Jpn., C02, 2001b (in Japanese with English abstract)

Ozawa, T., T. Tabei, and S. Miyazaki, Interplate coupling along the Nankai Trough off southwest Japan derived from GPS measurements, Geophys. Res. Lett., 26, 927-930, 1999.

Plafker, G., Alaskan earthquake of 1964 and Chilean earthquake of 1960: Implications for arc tectonics, J. Geophys. Res., 77, 901-923, 1972.

Sagiya, T. and W. Thatcher, Coseismic slip resolution along a plate boundary megathrust: The Nankai Trough, southwest Japan, J. Geophys. Res. 104, 1111-1129, 1999

Sato, K., M. Hashimoto, Y. Hoso, F. Ohya, S. Matsuo, S. Fujihara, H. Hirose, H. Hayashi, Y. Ooi, T. Okuda, K. Tadokoro, K. Hirahara, M. Ando, T. Yamada, H. Takiguchi, M. Abe, T. Tabei, H. Chikazoe, Y. Kakehi, Y. Itani, and M. Yamauchi, Evaluation of kinematic GPS positioning accuracy: (1) Different baseline length, Abstr. Joint Meet. Earth Planet. Sci., Dm-002, 2001.

Shinohara, M., E. Araki, T. Kanazawa, H. Mikada, M. Mochizuki, K. Suyehiro, and Y. Fukao, OHP network seafloor borehole observatoryNorthwestern Pacific basin, Abstr. Joint Meet. Earth Planet. Sci., Sd-003, 2000 
Spiess, F. N., C. D. Chadwell, J. A. Hildebrand, L. E. Young, G. H. Purcell, Jr., and H. Dragert, Precise GPS/Acoustic positioning of seafloor reference points for tectonic studies, Phys. Earth Planet. Inter., 108, 101-112, 1998.

Tadokoro, K., M. Ando, K. Sato, T. Yamada, T. Okuda, H. Katao, and K. Kishimoto, Development of an observation system for ocean bottom crustal deformation using an acoustic ranging-GPS Link, J. Geography, 110, 521-528, 2001 (in Japanese with English abstract).

Tanioka, Y. and K. Satake, Coseismic slip distribution of the 1946 Nankai earthquake and aseismic slip caused by the earthquake, Earth Planets
Space, 53, 235-241, 2001a.

Tanioka, Y. and K. Satake, Detailed coseismic slip distribution of the 1944 Tonankai earthquake estimated from tsunami waveforms, Geophys. Res. Lett., 28, 1075-1078, 2001b.

Thatcher, W., Silent slip on the Cascadia subduction interface, Science, 292, 1495-1496, 2001

T. Yamada (e-mail: takuji@rcep.dpri.kyoto-u.ac.jp), M. Ando, K. Tadokoro, K. Sato, T. Okuda, and K. Oike 